\title{
Updating ACSM's Recommendations for Exercise Preparticipation Health Screening
}

\author{
DEBORAH RIEBE ${ }^{1}$, BARRY A. FRANKLIN ${ }^{2}$, PAUL D. THOMPSON ${ }^{3}$, CAROL EWING GARBER $^{4}$, \\ GEOFFREY P. WHITFIELD ${ }^{5}$, MEIR MAGAL ${ }^{6}$, and LINDA S. PESCATELLO ${ }^{7}$ \\ ${ }^{1}$ Department of Kinesiology, University of Rhode Island, Kingston, RI; ${ }^{2}$ Department of Preventive Cardiology, Beaumont \\ Health Center, Royal Oak, MI; ${ }^{3}$ Department of Cardiology, Hartford Hospital, Hartford, CT; ${ }^{4}$ Teachers College, Columbia \\ University, New York, NY; ${ }^{5}$ No affiliation; ${ }^{6}$ Division of Mathematics and Sciences, North Carolina Wesleyan College, \\ Rocky Mount, NC; and ${ }^{7}$ Department of Kinesiology, University of Connecticut, Storrs, CT
}

\begin{abstract}
RIEBE, D., B. A. FRANKLIN, P. D. THOMPSON, C. E. GARBER, G. P. WhitFIELD, M. MAGAL, and L. S. PESCATELlO. Updating ACSM's Recommendations for Exercise Preparticipation Health Screening. Med. Sci. Sports Exerc., Vol. 47, No. 8, pp. 2473-2479, 2015. The purpose of the American College of Sports Medicine's (ACSM) exercise preparticipation health screening process is to identify individuals who may be at elevated risk for exercise-related sudden cardiac death and/or acute myocardial infarction. Recent studies have suggested that using the current ACSM exercise preparticipation health screening guidelines can result in excessive physician referrals, possibly creating a barrier to exercise participation. In addition, there is considerable evidence that exercise is safe for most people and has many associated health and fitness benefits; exercise-related cardiovascular events are often preceded by warning signs/symptoms; and the cardiovascular risks associated with exercise lessen as individuals become more physically active/fit. Consequently, a scientific roundtable was convened by the ACSM in June 2014 to evaluate the current exercise preparticipation health screening recommendations. The roundtable proposed a new evidence-informed model for exercise preparticipation health screening on the basis of three factors: 1) the individual's current level of physical activity, 2) presence of signs or symptoms and/or known cardiovascular, metabolic, or renal disease, and 3) desired exercise intensity, as these variables have been identified as risk modulators of exercise-related cardiovascular events. Identifying cardiovascular disease risk factors remains an important objective of overall disease prevention and management, but risk factor profiling is no longer included in the exercise preparticipation health screening process. The new ACSM exercise preparticipation health screening recommendations reduce possible unnecessary barriers to adopting and maintaining a regular exercise program, a lifestyle of habitual physical activity, or both, and thereby emphasize the important public health message that regular physical activity is important for all individuals. Key Words: PRESCREENING, SUDDEN CARDIAC DEATH, PHYSICAL ACTIVITY, CARDIOVASCULAR DISEASE
\end{abstract}

$\mathrm{R}$ egular physical activity and structured exercise are associated with numerous health benefits including a lower risk of cardiovascular disease (CVD), type 2 diabetes mellitus, some forms of cancer, and age-adjusted all-cause mortality, among others $(19,26,33,43)$. Despite these well-known health benefits, physical inactivity is a global pandemic that has been identified as one of the four leading contributors to premature mortality $(22,26)$. Although efforts to promote physical activity at both the

Address for correspondence: Deborah Riebe, Ph.D., F.A.C.S.M., Department of Kinesiology, University of Rhode Island, 24 West Independence Way, Kingston, RI 02881; E-mail: debriebe@uri.edu.

Submitted for publication February 2015.

Accepted for publication March 2015.

0195-9131/15/4708-2473/0

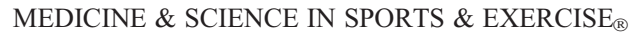

Copyright $(C) 2015$ by the American College of Sports Medicine

DOI: 10.1249 MSS.0000000000000664 individual and community level have had some success, the prevalence of physical inactivity remains high $(7,8,36,50)$. Physical activity is a complex behavior influenced by demographic, biological, cognitive, emotional, sociocultural, and environmental factors (3). Accordingly, individuals face numerous barriers in both the adoption and maintenance of a regular exercise program, as evidenced by high levels of physical inactivity $(2,3)$.

A possible barrier to becoming physically active is the requirement for exercise preparticipation health screening, which may involve a visit to a health care provider and/or diagnostic testing to potentially identify underlying CAD and other occult CVD $(3,16,46)$. Unnecessary referral to health care providers for screening may lead to a high rate of false-positive exercise test responses in some populations, necessitating medical follow-up and additional noninvasive/ invasive studies when they are not needed. Such studies can place unnecessary financial and other burdens on the individual and health care system $(16,32)$. Vigorous-intensity 
exercise does have a small but measurable acute risk of CVD complications; therefore, mitigating this risk in susceptible individuals is important $(31,39,40)$. The exercise preparticipation health screening process should provide prudent assessment while minimizing barriers to adopting a physically active lifestyle.

The existing American College of Sports Medicine (ACSM) exercise preparticipation health screening recommendations stipulate that persons at moderate risk for CVD undergo a medical examination prior to starting a vigorous (achieving $\geq 60 \%$ oxygen uptake reserve $\left(\dot{\mathrm{VO}}_{2} \mathrm{R}\right)$ or heart rate (HR) reserve (HRR), or $\geq 6$ METs) exercise program $(2,19)$. An individual is considered at moderate risk for CVD if he/she is asymptomatic and has two or more CVD risk factors (2). ACSM also recommends that persons at high risk for CVD undergo a medical examination and diagnostic exercise testing before beginning either a moderate-intensity $(40 \%$ to $<60 \%$ $\dot{\mathrm{VO}}_{2} \mathrm{R}$ or HRR; 3 to $<6$ METs) or a vigorous-intensity exercise program. Lastly, an individual is considered at high risk for CVD if they are symptomatic or have known cardiovascular, pulmonary, metabolic, or renal disease (2).

The current ACSM exercise preparticipation health screenng recommendations were largely formulated to reduce the likelihood of "at-risk" individuals experiencing serious exerciserelated cardiovascular events, including sudden cardiac death (SCD) and/or acute myocardial infarction (AMI). Although the risk of an acute cardiovascular event is transiently increased during vigorous-intensity exercise relative to rest, especially in habitually sedentary individuals with known or occult CVD who engage in unaccustomed strenuous physical exertion, the absolute and relative risks of a cardiovascular event during exercise are extremely low even during vigorousintensity exercise in asymptomatic individuals $(35,39,41)$. In addition, the risk of an acute cardiovascular event decreases with increasing volumes of regular exercise $(31,39)$ and among people who are physically fit (40). Finally, recent reports have suggested that using current prescreening algorithms can result in excessive referrals to physicians for medical clearance, which could be a barrier to adopting and maintaining a regular exercise program $(24,45,48)$.

Because motivating people to be physically active is a significant challenge, exercise preparticipation health screening recommendations should not present unnecessary obstacles that deter people from adopting and maintaining a regular exercise program. In addition, because of increasing evidence that exercise is safe for most people, it has many associated health benefits, exercise-related cardiovascular events are often preceded by warning signs/symptoms, and the cardiovascular risks associated with exercise lessen as people become more physically active/fit, leading experts from the College recognized the need for evaluation and refinement of the existing ACSM preparticipation health screening recommendations $(5,19,40,44)$. Accordingly, in June 2014, the ACSM convened a scientific roundtable (i.e., expert panel) to establish best practices in the exercise preparticipation health screening process.

The scientific roundtable consisted of experts in risk assessment, preventive cardiology, general cardiology, public health, exercise physiology, and geriatrics as well as practitioners from the fields of medicine, clinical exercise physiology, and health fitness/prevention. After a review of the scientific literature and extensive discussion, members of the roundtable proposed an evidence-informed model for the new ACSM exercise preparticipation health screening recommendations described in this consensus statement. In this consensus statement, we present the new ACSM exercise preparticipation health screening recommendations, summarize the changes that were made from the previous ACSM recommendations, and provide the fundamental physiological and clinical reasons for the changes that were made. The new ACSM recommendations are not a replacement for sound clinical judgment, and decisions about referral to a health care provider for medical clearance before the initiation of an exercise program should continue to be made on an individual basis.

\section{THE NEW ACSM EXERCISE PREPARTICIPATION HEALTH SCREENING RECOMMENDATIONS}

The goals of the new ACSM exercise preparticipation health screening process are to identify individuals 1) who should receive medical clearance before initiating an exercise program or increasing the frequency, intensity, and/or volume of their current program, 2) with clinically significant disease(s) who may benefit from participating in a medically supervised exercise program, and 3) with medical conditions that may require exclusion from exercise programs until those conditions are abated or better controlled (2).

The new ACSM exercise preparticipation health screening recommendations differ from previous recommendations in several ways (Table 1). CVD risk factor assessment and risk classification are no longer part of the exercise preparticipation health screening process per se. Instead, the

TABLE 1. Summary of major changes in ACSM's exercise preparticipation health screening procedures.

- The previous ACSM exercise preparticipation health screening process was based on the following: 1) the number of CVD risk factors and 2) presence of signs or symptoms and/or known cardiovascular, metabolic, renal, and/or pulmonary disease. The new ACSM exercise preparticipation health screening process is now based on the following: 1) the individual's current level of physical activity, 2) presence of signs or symptoms and/or known cardiovascular, metabolic, or renal disease, and 3) desired exercise intensity, as these three factors have been identified as important risk modulators of exercise-related cardiovascular events.

- Identifying and controlling CVD risk factors continue to be important objectives of overall cardiovascular and metabolic disease prevention and management; however, the CVD risk factor profile is no longer included in the decision making for referral to a health care provider before initiating a moderate- to vigorous-intensity exercise program.

- The classification of individuals as having low, moderate, or high risk of CVD is no longer included in the new ACSM exercise preparticipation health screening process. Specific recommendations for a medical examination or exercise testing based on risk classification is no longer included. Instead, individuals are referred to their health care provider for medical clearance, defined as approval from a health care professional to engage in exercise.

- Individuals with pulmonary disease are not automatically referred for medical clearance before initiation of an exercise program. 
new ACSM exercise preparticipation health screening process focuses on 1) the individual's current level of physical activity, 2) presence of signs or symptoms of known cardiovascular, metabolic, or renal disease, and 3) the desired exercise intensity, as these variables have been identified as risk modulators of exercise-related cardiovascular events $(2,6,19)$. Several key findings formed the rationale for the current changes outlined in Table 1. They are presented as follows.

Risk of SCD and AMI. It is well established that the transient risks of SCD and AMI are substantially higher during acute vigorous physical exertion as compared with those during rest $(1,31)$. Retrospective and prospective data suggest that vigorous-intensity physical activity transiently increases the risk of nonfatal AMI and SCD approximately sixfold (31) to 17-fold (1) as compared with resting behavior.

Although the relative risks of SCD and AMI are higher during sudden vigorous physical exertion versus those at rest, the absolute risk of these events is very low. Prospective evidence from the Physicians' Health Study and Nurses' Health Study suggests that SCD occurs every 1.5 million episodes of vigorous physical exertion in men (1) and every 36.5 million hours of moderate-to-vigorous exertion in women (47). Retrospective analyses also support the rarity of these events. Thompson et al. (41) reported one death per $396,000 \mathrm{~h}$ of jogging. An analysis of exercise-related cardiovascular events among participants at YMCA sports centers found one death per 2,897,057 person-hours, although exercise intensity was not documented (30). Kim et al. (25) studied more than 10 million marathon and halfmarathon runners and identified an overall cardiac arrest incidence rate of one per 184,000 runners and an SCD incidence rate of one per 256,000 runners, which translate to 0.20 cardiac arrests and 0.14 SCD per 100,000 estimated runner-hours. Collectively, these studies illustrate the rarity of CVD events during exercise and suggest that exercise is safe for most people. Because there are few data regarding cardiovascular complications during resistance training, this risk cannot currently be determined but seems to be low $(20,21,49)$.

Research into exercise-related SCD and AMI has revealed several variables associated with increased risk of cardiovascular events. Exercise-related cardiovascular events are often preceded by warning signs or symptoms (40). Autopsy studies of those who experienced SCD suggest that underlying CAD contributed to most cases among adults age $35 \mathrm{yr}$ and older, whereas exertion-related SCD in younger people is often attributed to structural cardiovascular abnormalities, most notably, hypertrophic cardiomyopathy (27). However, research on exercise-associated SCD and AMI has focused primarily on the effects of vigorous- to near maximal-intensity physical activity (35). Less is known about the risks of SCD and AMI during light- to moderate-intensity exercise, but they are assumed to be substantially lower (44). Moreover, in virtually all studies, habitual physical activity was inversely related to the likelihood of SCD and/or AMI occurring during or immediately after vigorous-intensity exercise $(1,12,31,39)$.
Although increasing age is a risk factor for CVD (men, $\geq 45 \mathrm{yr}$; women, $\geq 55 \mathrm{yr}$ ), there is no evidence that age per se is a strong predictor of exercise-associated SCD and AMI (20), and the referral of individuals for medical clearance solely on the basis of age has been shown to result in superfluous health care referrals $(6,19,46)$.

Physical activity status. Physically inactive individuals are at greater total risk for acute cardiac events than their physically active counterparts $(18,44)$. To put the risk versus protective benefit of exercise into perspective, it is important to reemphasize that the absolute risk of exercise-related acute cardiac events is extremely low. The relative risk of SCD and AMI during vigorous- to near maximal-intensity exercise is directly related to the presence of CVD and/or exertional symptoms and inversely related to the individual's habitual level of physical activity. For example, the Onset Study (31) showed that the risk of AMI during vigorous intensity exercise was almost twice that at rest even for individuals who exercised vigorously for $1 \mathrm{~h}$ on 5 or more days per week. However, this study also showed that the risk of AMI for habitually inactive individuals was 50 times higher than that for the most physically active individuals (Fig. 1). Regular exercise reduces the 24-h risk of CVD events by approximately $50 \%$ $(4,34)$, meaning that the regular exerciser's relative risk is significantly lower during both vigorous-intensity exercise and over the remainder of the day, highlighting the clear net benefit of regular physical activity.

A recent meta-analysis reported a fivefold increased risk of SCD and 3.5-fold increased risk of AMI during vigorousintensity physical activity ( $\geq 6$ METs) (12). However, in cohorts with the lowest habitual physical activity levels, the

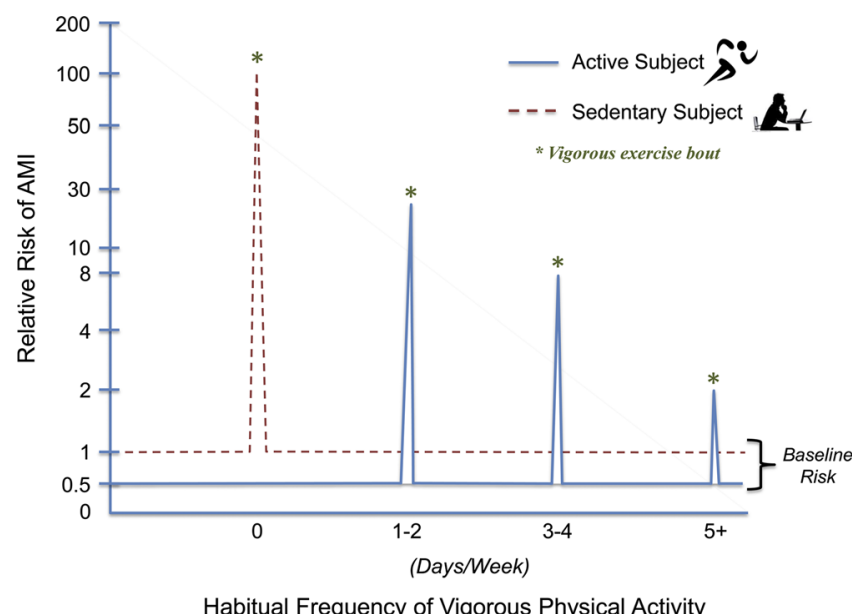

FIGURE 1-Relative risk of AMI at rest (baseline risk) and during vigorous physical activity ( $\geq 6$ METs) in sedentary and physically active individuals, with specific reference to the habitual frequency of vigorous exertion (d·wk ${ }^{-1}$ ). (Adapted from Mittleman MA, Maclure M, Tofler GH, Sherwood JB, Goldberg RJ, Muller JE. Triggering of acute myocardial infarction by heavy physical exertion. Protection against triggering by regular exertion. Determinants of Myocardial Infarction Onset Study Investigators. N Engl J Med. 1993;329(23):1677-1683. Used with permission. Adapted from Franklin BA. Preventing exerciserelated cardiovascular events: is a medical examination more urgent for physical activity or inactivity? Circulation. 2014;129:1081-1084. Used with permission.) 
relative risk for exertion-related AMI ranged from 4.5 to 107, indicating a substantial increased risk in physically inactive individuals; in contrast, the corresponding relative risk in the groups with the highest habitual physical activity levels was only $0.86-3.3$, suggesting much smaller increases in risk in active individuals. Furthermore, these authors found that for every additional exercise bout per week, there was 30\% reduction in the risk of SCD and $45 \%$ reduction in the risk of AMI during physical activity (12).

The previously referenced findings are consistent with the conclusion of the 2008 Physical Activity Guidelines Advisory Committee and ACSM that the overall cardiovascular benefits of regular physical activity far outweigh the modestly increased acute exercise risks (44). These findings are also consistent with the recommendations of Bredin et al. (6) and Warburton et al. (46). Collectively, these studies suggest that the risk of exercise is highest among inactive individuals and those with known or occult CAD who perform unaccustomed vigorous-intensity physical activity.

CVD risk factor assessment. Two important considerations led to removing CVD risk factor assessment from the new ACSM exercise preparticipation health screening process. First, the high prevalence of CVD risk factors among adults, combined with the extreme rarity of exercise-related SCD and AMI, suggests that the ability to predict these rare events by assessing CVD risk factors is low (42). For example, the Centers for Disease Control and Prevention estimate that 65 million US adults have hypertension (11) and 71 million adults have high LDL cholesterol (9). In contrast, 600,000 people die from heart disease each year and only a small fraction of those are due to exercise-associated SCD and AMI (10). Therefore, using CVD risk factors to identify those susceptible to exercise-associated SCD or AMI as ACSM has done in the past is unlikely to be effective in achieving its intended purpose. Second, recent evidence suggests that conventional CVD risk factor-based exercise preparticipation health screening may be overly conservative because of the high prevalence of CVD risk factors. A recent study found that $95 \%$ of men and women over $40 \mathrm{yr}$ of age would be advised to consult a physician before exercise based upon the previous risk factor-based exercise preparticipation health screening process (48).

Identifying and controlling CVD risk factors continue to be important objectives of overall cardiovascular and metabolic disease prevention and management, and exercise professionals are encouraged to complete a CVD risk factor assessment with their patients/clients $(2,14)$. However, risk factor profiling is no longer included in the exercise preparticipation health screening process as a determinant of medical clearance for exercise. Nonetheless, some evidence suggests that diabetes mellitus and renal disease may be associated with exercise-related SCD and AMI $(1,31)$, and specific recommendations for individuals with these comorbid conditions are incorporated into the new procedures.

Risk classification and medical clearance. The previous ACSM exercise preparticipation health screening recommendations classified individuals as having low, moderate, or high risk for CVD on the basis of the number of CVD risk factors and the presence of signs or symptoms and/or cardiovascular, metabolic, renal, or pulmonary disease (2). The recommendation for a medical examination or diagnostic exercise test before engaging in exercise was then based on this risk classification scheme. Because CVD risk factor profiling has been removed as part of the new ACSM exercise preparticipation health screening process, individuals no longer need to be classified into risk categories. Instead, individuals are referred to health care providers for medical clearance, defined as approval from a health care professional to engage in exercise, on the basis of the presence of signs or symptoms and/or known cardiovascular, metabolic, or renal disease and physical activity status. The term "medical clearance" has replaced specific recommendations for a medical examination or exercise test because it should be the health care provider who decides what evaluation, if any, is appropriate before the initiation of a moderate- to vigorous-intensity exercise program.

There is a lack of evidence that medical clearance and exercise testing (28) are effective in mitigating the risk of exercise-related cardiovascular events. There is also a lack of consensus among major organizations regarding the extent of medical evaluation needed as part of the exercise preparticipation health screening process (2). The American College of Cardiology/American Heart Association recommend exercise testing before engaging in moderate- or vigorous-intensity exercise when the risk of CVD is increased but recognize that these recommendations are based on conflicting evidence and divergent expert opinions (15). The 2008 Physical Activity Guidelines Advisory Committee report to the Secretary of Health and Human Services (44) states that "symptomatic persons or those with CVD, diabetes, or other active chronic conditions who want to begin engaging in vigorous physical activity and who have not already developed a physical activity plan with their health care provider may wish to do so," but does not mandate such medical contact. More recently, the U.S. Preventive Services Task Force recommends against the use of routine diagnostic resting or exercise electrocardiography as a screening tool in asymptomatic individuals who are at low risk of CVD events and concluded that there is insufficient evidence to evaluate the benefits and harm of exercise testing before initiating a PA program and did not make specific recommendations regarding the need for exercise testing for individuals at intermediate and high risk for CVD events (32). The ACSM does not recommend abandoning all medical evaluation as part of the exercise preparticipation health screening process. Rather, the new recommendations provide guidance to identify those at highest risk for exercise-related AMI or SCD for referral to a health care provider to recommend medical clearance on the basis of their clinical judgment.

Pulmonary disease. Individuals with pulmonary disease are no longer automatically referred for medical clearance because pulmonary disease does not increase the risks of nonfatal or fatal cardiovascular complications during 
or immediately after exercise; in fact, it is the associated inactive and sedentary lifestyle of many patients with pulmonary disease that may increase the risk of these events (23). However, chronic obstructive pulmonary disease (COPD) and CVD are often comorbid because of the common risk factor of smoking, and the presence of COPD in current or former smokers is an independent predictor of overall cardiovascular events (13). Thus, careful attention to the presence of signs and symptoms of cardiovascular and metabolic disease is warranted in individuals with COPD during the exercise preparticipation health screening process. Nevertheless, despite this change, the presence of pulmonary or other diseases remains an important consideration in determining the safest and most effective exercise prescription.

\section{THE NEW EXERCISE PREPARTICIPATION HEALTH SCREENING PROCESS ALGORITHM}

The new logic model for the exercise preparticipation screening process is presented in Figure 2. In this model, regularly physically active asymptomatic individuals without known cardiovascular (i.e., cardiac, peripheral artery, cerebrovascular), metabolic (i.e., type 1 or 2 diabetes mellitus), or renal disease may continue their usual exercise and progress gradually as tolerated according to the accepted ACSM exercise prescription guidelines $(2,19)$. Physically active asymptomatic individuals with known cardiovascular, metabolic, or renal disease whose health care provider has cleared them to exercise within the last 12 months do not need to revisit their health care provider to continue a moderate-intensity exercise

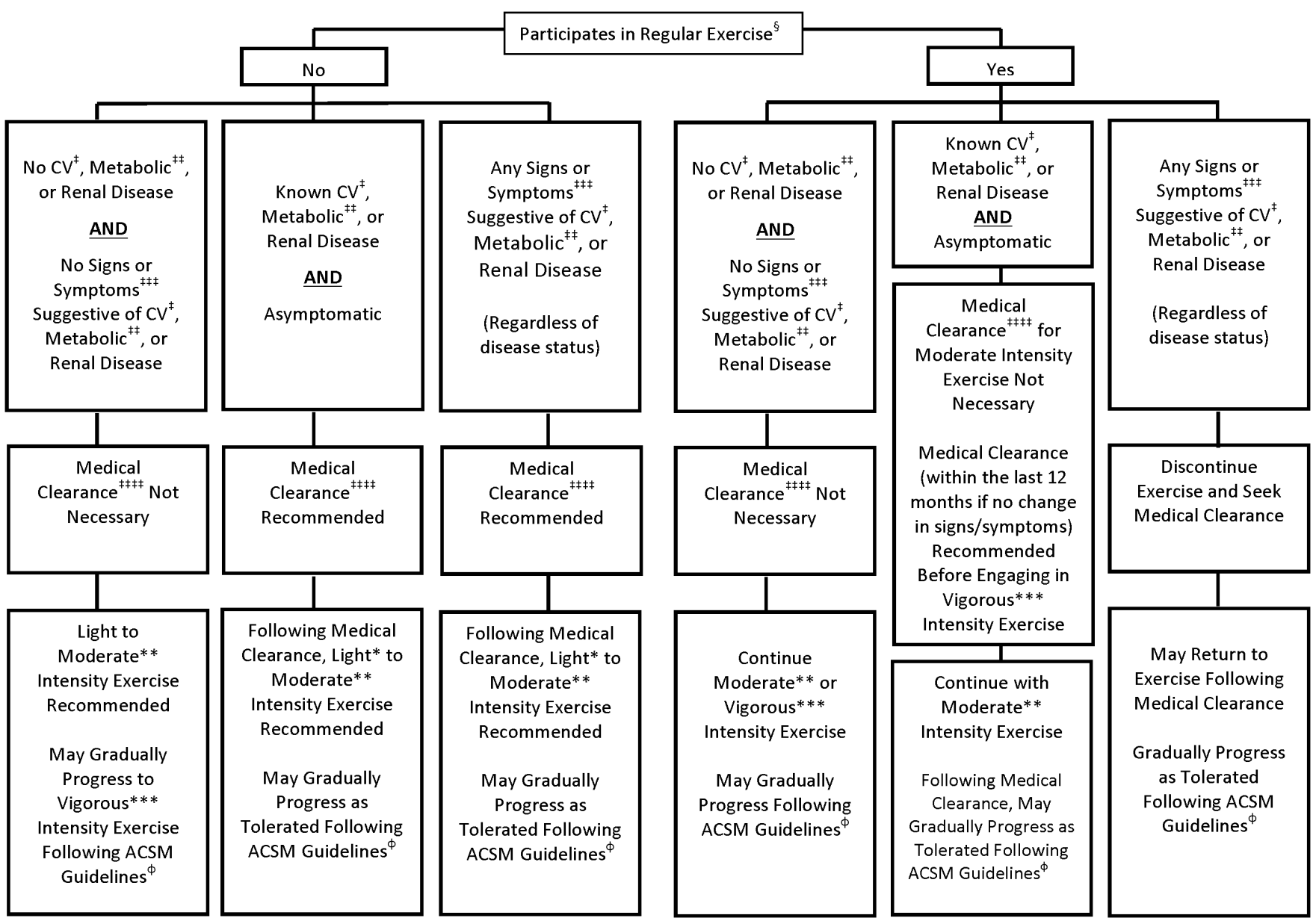

FIGURE 2-Exercise preparticipation health screening logic model for aerobic exercise participation.

$\S$ Exercise participation, performing planned, structured physical activity at least 30 min at moderate intensity on at least 3 d.wk ${ }^{-1}$ for at least the last 3 months.

*Light-intensity exercise, $30 \%$ to $<40 \%$ HRR or $\dot{\mathbf{V}} \mathbf{O}_{2} \mathbf{R}, 2$ to $<3$ METs, 9-11 RPE, an intensity that causes slight increases in HR and breathing. $* *$ Moderate-intensity exercise, $40 \%$ to $<60 \%$ HRR or $\mathrm{VO}_{2} \mathrm{R}, 3$ to $<6$ METs, $12-13$ RPE, an intensity that causes noticeable increases in $\mathrm{HR}$ and breathing.

$* * *$ Vigorous-intensity exercise $\geq 60 \%$ HRR or $\dot{\mathrm{V}} \mathrm{O}_{2} \mathrm{R}, \geq 6 \mathrm{METs}, \geq 14 \mathrm{RPE}$, an intensity that causes substantial increases in $\mathrm{HR}$ and breathing. CVD, cardiac, peripheral vascular, or cerebrovascular disease.

t+Metabolic disease, type 1 and 2 diabetes mellitus.

$\$+$ Signs and symptoms, at rest or during activity; includes pain, discomfort in the chest, neck, jaw, arms, or other areas that may result from ischemia; shortness of breath at rest or with mild exertion; dizziness or syncope; orthopnea or paroxysmal nocturnal dyspnea; ankle edema; palpitations or tachycardia; intermittent claudication; known heart murmur; or unusual fatigue or shortness of breath with usual activities.

+++ Medical clearance, approval from a health care professional to engage in exercise.

ФACSM Guidelines, see ACSM's Guidelines for Exercise Testing and Prescription, 9th edition, 2014. 
program, unless they develop resting or exertional symptoms of cardiovascular, metabolic, or renal disease or experience a change in health status. Finally, it is recommended that physically active individuals who develop signs or symptoms of cardiovascular, metabolic, or renal disease discontinue exercise and seek medical clearance before resuming exercise of any intensity.

Physically inactive but otherwise healthy asymptomatic persons may begin light- to moderate-intensity exercise without medical clearance and, in the absence of symptoms, progress gradually in intensity as recommended by current ACSM exercise prescription guidelines $(2,19)$. Physically inactive individuals with known cardiovascular, metabolic, or renal disease and/or those with signs or symptoms suggestive of these diseases should seek medical clearance before starting an exercise program, regardless of the intensity.

\section{CONCLUSIONS}

There is voluminous evidence that risks of remaining physically inactive, especially in those with chronic disease, are substantial $(38,45)$. The new ACSM exercise preparticipation health screening recommendations emphasize the important public health message of regular physical activity for all and seeks to remove unnecessary barriers to adopting and maintaining a structured exercise program, a lifestyle embracing habitual physical activity, or both. The risk for acute exercise-related cardiovascular events is highest among habitually sedentary individuals with known or occult CVD who perform unaccustomed vigorous-intensity physical activity. Hence, the new ACSM exercise preparticipation health screening guidelines focus on assessing 1) the individual's current level of physical activity, 2) presence of signs or symptoms and/or known cardiovascular, metabolic, or renal disease, and 3) desired exercise intensity.

\section{REFERENCES}

1. Albert CM, Mittleman MA, Chae CU, Lee IM, Hennekens CH, Manson JE. Triggering of sudden death from cardiac causes by vigorous exertion. $N$ Engl J Med. 2000;343(19):1355-61.

2. American College of Sports Medicine; Pescatello LS, Arena R, Riebe D, Thompso PD, editors. ACSM's Guidelines for Exercise Testing and Prescription. 9th ed. Philadelphia (PA): Wolters Kluwer/Lippincott Williams \& Wilkins Health; 2014.

3. Bauman AE, Sallis JF, Dzewaltowski DA, Owen N. Toward a better understanding of the influences on physical activity: the role of determinants, correlates, causal variables, mediators, moderators, and confounders. Am J Prev Med. 2002;23(2 Suppl):5-14.

4. Berlin JA, Colditz GA. A meta-analysis of physical activity in the prevention of coronary heart disease. Am J Epidemiol. 1990;132:612-28.

5. Bowles DK, Laughlin MH. Mechanisms of beneficial effects of physical activity on atherosclerosis and coronary heart disease. J Appl Physiol (1985). 2011;111(1):308-10.

6. Bredin SS, Gledhill N, Jamnik VK, Warburton DE. PAR-Q+ and ePARmed-X+: new risk stratification and physical activity clearance strategy for physicians and patients alike. Can Fam Physician. 2013;59:273-7.
In addition, the hazard of exercise-related cardiovascular events may more likely be reduced by careful attention to a safe and effective exercise prescription that 1) addresses the frequency, intensity, time, and type-volume and progression or FITT-VP principle of exercise prescription, incorporating a progressive transitional phase (i.e., 2-3 months), during which the duration and intensity of exercise are gradually increased, 2) advocates appropriate warm-up and cooldown procedures, 3) promotes education of warning signs/symptoms (e.g., chest pain or pressure, lightheadedness, heart palpitations/arrhythmias, unusual shortness of breath), 4) encourages sedentary individuals to engage in regular brisk walking so as to move them out of the least physically fit and least physically active cohort, and 5) counsels physically inactive individuals to avoid unaccustomed vigorous- to near maximal-intensity physical activity $(6,17,19,29,37,46)$.

The new ACSM exercise preparticipation health screening recommendations are research informed when available and seek to simplify the process by eliminating the need for medical clearance and/or exercise testing in many individuals, especially when low- to moderate-intensity exercise is contemplated. The upcoming ACSM's Guidelines for Exercise Testing and Prescription, 10th edition, will provide updated and expanded information on the new ACSM exercise preparticipation health screening process and recommendations.

The Exercise Preparticipation Health Screening Roundtable was generously supported by the ACSM. Expert panel members included David M. Buchner, M.D., M.P.H., F.A.C.S.M.; Joanne EickhoffSchemek, Ph.D.; Carol Ewing Garber, Ph.D., F.A.C.S.M.; Barry A. Franklin, Ph.D., F.A.C.S.M.; Adrian Hutber, Ph.D.; Elizabeth A. Joy, M.D., M.P.H., F.A.C.S.M.; Gary Liguori, Ph.D., F.A.C.S.M.; Meir Magal, Ph.D., F.A.C.S.M.; Linda S. Pescatello, Ph.D., F.A.C.S.M.; Deborah Riebe, Ph.D., F.A.C.S.M.; Thomas Spring, M.S.; Paul D. Thompson, M.D., F.A.C.S.M.; Walter R. Thompson, Ph.D.; Darren E. R. Warburton, Ph.D.; and Geoffrey P. Whitfield, Ph.D., F.A.C.S.M. Several ACSM staff played key advisory, leadership, and administrative roles, including Jim Whitehead, Richard Cotton, Katie Feltman, and Jane Gleason-Senior.

7. Buckler A, Servies T; US Preventive Services Task Force. Behavioral counseling interventions to promote a healthful diet and physical activity for cardiovascular disease prevention in adults. Am Fam Physician. 2013;87(12):869-70.

8. Centers for Disease Control and Prevention. Adult participation in aerobic and muscle-strengthening physical activities-United States, 2011. MMWR Morb Mortal Wkly Rep. 2001;62(17): 326-30.

9. Centers for Disease Control and Prevention. Cholesterol facts and statistics. 2012. Available from: http://www.cdc.gov/cholesterol/ facts.htm. Accessed 3 Feb 2015.

10. Centers for Disease Control and Prevention. Heart disease facts. 2014. Available from: http://www.cdc.gov/heartdisease/facts.htm. Accessed 3 Feb 2015.

11. Centers for Disease Control and Prevention. High blood pressure facts. Available from: http://www.cdc.gov/bloodpressure/facts.htm. Accessed 3 Feb 2015.

12. Dahabreh IJ, Paulus JK. Association of episodic physical and sexual activity with triggering of acute cardiac events: systematic review and meta-analysis. JAMA. 2011;305(12):1225-33. 
13. de Barros e Silva PG, Califf RM, Sun J, et al. Chronic obstructive pulmonary disease and cardiovascular risk: insights from the NAVIGATOR trial. Int J Cardiol. 2014;176(3):1126-8.

14. Eckel RH, Jakicic JM, Ard JD, et al.; American College of Cardiology/American Heart Association Task Force on Practice Guidelines. 2013 AHA/ACC guideline on lifestyle management to reduce cardiovascular risk: a report of the American College of Cardiology/American Heart Association Task Force on Practice Guidelines. J Am Coll Cardiol. 2014;63:2960-84.

15. Fletcher GF, Ades PA, Kligfield P, et al. Exercise standards for testing and training: a scientific statement from the American Heart Association. Circulation. 2013;128(8):873-934.

16. Franklin BA. Preventing exercise-related cardiovascular events: is a medical examination more urgent for physical activity or inactivity? Circulation. 2014;129:1081-4.

17. Franklin BA, Billecke S. Putting the benefits and risks of aerobic exercise in perspective. Curr Sports Med Rep. 2012;11(4):201-8.

18. Franklin BA, McCullough PA. Cardiorespiratory fitness: an independent and additive marker of risk stratification and health outcomes. Mayo Clin Proc. 2009;84(9):776-9.

19. Garber CE, Blissmer B, Deschenes MR, et al.; American College of Sports Medicine. Position Stand: quantity and quality of exercise for developing and maintaining cardiorespiratory, musculoskeletal, and neuromotor fitness in apparently healthy adults: guidance for prescribing exercise. Med Sci Sports Exerc. 2011;43(7):1334-59.

20. Goodman JM, Thomas SG, Burr J. Evidence-based risk assessment and recommendations for exercise testing and physical activity clearance in apparently healthy individuals. Appl Physiol Nutr Metab. 2011;36:S14-32.

21. Gordon NF, Kohl HW 3rd, Pollock ML, Vaandrager H, Gibbons LW, Blair SN. Cardiovascular safety of maximal strength testing in healthy adults. Am J Cardiol. 1995;76(11):851-3.

22. Hallal PC, Andersen LB, Bull FC, Gothold R, Haskell W, Ekelund U. Global physical activity level: surveillance progress, pitfalls, and progress. Lancet. 2012;380:247-57.

23. Hill K, Gardiner P, Cavalheri V, Jenkins S, Healy G. Physical activity and sedentary behaviour: applying lessons to chronic obstructive pulmonary disease. Intern Med J. 2015;45(5):474-82.

24. Jamnik VJ, Warburton DE, Makrski J, et al. Enhancing the effectiveness of clearance for physical activity participation; background and overall purpose. Appl Physiol Nutr Metab. 2011; $36: \mathrm{S} 3-13$.

25. Kim JH, Malhotra R, Chiampas G, et al.; Race Associated Cardiac Arrest Event Registry (RACER) Study Group. Cardiac arrest during long-distance running races. $N$ Engl J Med. 2012;366(2): $130-40$.

26. Kohl HW 3rd, Craig CL, Lambert EV, et al. The pandemic of physical inactivity: global action for public health. Lancet. 2012; 380:294-305.

27. Kohl HW 3rd, Powell KE, Gordon NF, Blair SN, Paffenbarger RS Jr. Physical activity, physical fitness, and sudden cardiac death. Epidemiol Rev. 1992;14:37-58.

28. Lauer M, Froelicher ES, Williams M, Kligfield P. Exercise testing in asymptomatic adults: a statement for professionals from the American Heart Association Council on Clinical Cardiology, Subcommittee on Exercise, Cardiac Rehabilitation, and Prevention. Circulation. 2005;112:771-6.

29. Lee DC, Pate RR, Lavie CJ, Sui X, Church TS, Blair SN. Leisuretime running reduces all-cause and cardiovascular mortality risk. J Am Coll Cardiol. 2014;64:472-81.

30. Malinow M, McGarry D, Kuehl K. Is exercise testing indicated for asymptomatic active people? J Cardiac Rehabil. 1984;4:376-9.

31. Mittleman MA, Maclure M, Tofler GH, Sherwood JB, Goldberg RJ, Muller JE. Triggering of acute myocardial infarction by heavy physical exertion. Protection against triggering by regular exertion. Determinants of Myocardial Infarction Onset Study Investigators. N Engl J Med. 1993;329(23):1677-83.
32. Moyer VA; US Preventive Services Task Force. Screening for coronary heart disease with electrocardiography: U.S. Preventive Services Task Force recommendation statement. Ann Intern Med. 2012;157(7):512-8.

33. Naci H, Ioannidis JP. Comparative effectiveness of exercise and drug interventions on mortality outcomes: metaepidemiological study. BMJ. 2013;347:f5577.

34. Powell KE, Thompson PD, Caspersen CJ, Kendrick JS. Physical activity and the incidence of coronary heart disease. Annu Rev Public Health. 1987;8:253-87.

35. Rognmo Ø, Moholdt T, Bakken H. Cardiovascular risk of highversus moderate-intensity aerobic exercise in coronary heart disease patients. Circulation. 2012;126(12):1436-40.

36. Roux L, Pratt M, Tengs TO, et al. Cost effectiveness of communitybased physical activity interventions. Am J Prev Med. 2008;35(6):578-88.

37. Sallis R, Franklin B, Joy L, Ross R, Sabgir D, Stone J. Strategies for promoting physical activity in clinical practice. Prog Cardiovasc Dis. 2015;57:375-86.

38. Sattelmair J, Pertman J, Ding EL, Kohl HW 3rd, Haskell W, Lee IM. Dose response between physical activity and risk of coronary heart disease: a meta-analysis. Circulation. 2011;124(7):789-95.

39. Siscovick DS, Weiss NS, Fletcher RH, Lasky T. The incidence of primary cardiac arrest during vigorous exercise. $N$ Engl $J$ Med. 1984;311(14):874-7.

40. Thompson PD, Franklin BA, Balady GJ, et al. Exercise and acute cardiovascular events placing the risks into perspective: a scientific statement from the American Heart Association Council on Nutrition, Physical Activity, and Metabolism and the Council on Clinical Cardiology. Circulation. 2007;115(17):2358-68.

41. Thompson PD, Funk EJ, Carleton RA, Sturner WQ. Incidence of death during jogging in Rhode Island from 1975 through 1980. JAMA. 1982;247(18):2535-8.

42. Thompson PD, Stern MP, Williams P, Duncan K, Haskell WL, Wood PD. Death during jogging or running. A study of 18 cases. JAMA. 1979;242(12):1265-7.

43. United States Department of Health and Human Services. 2008 Physical activity guidelines for Americans [Internet]. Washington (DC): ODPHP Publications No. U0036 [cited 2014 Sep 25]. Available from: http://www.health.gov/paguidelines/.gov/paguidelines/pdf/paguide.pdf.

44. United States Department of Health and Human Services. Physical activity guidelines advisory committee report 2008 [Internet]. Washington (DC): ODPHP Publications No. U0049 [cited 2014 Sep 25]. Available from: http://www.health.gov/paguidelines/ Report/pdf/CommitteeReport.pdf.

45. Warburton DE, Charlesworth S, Ivey A, Nettlefold L, Bredin SS. A systematic review of the evidence for Canada's physical activity guidelines for adults. Int J Behav Nutr Phys Act. 2010;7(1):39.

46. Warburton DE, Gledhill N, Jamnik VK, et al. Evidence-based risk assessment and recommendations for physical activity clearance: consensus document 2011. Appl Physiol Nutr Metab. 2011;36:S266-98.

47. Whang W, Manson JE, Hu FB, et al. Physical exertion, exercise, and sudden cardiac death in women. JAMA. 2006;295(12):1399-403.

48. Whitfield GP, Pettee Gabriel KK, Rahbar MH, Kohl HW 3rd. Application of the American Heart Association/American College of Sports Medicine Adult Preparticipation Screening Checklist to a nationally representative sample of US adults aged $\geq 40$ years from the National Health and Nutrition Examination Survey 2001 to 2004. Circulation. 2014;129(10):1113-20.

49. Williams MA, Haskell WL, Ades PA, et al.: American Heart Association Council on Clinical Cardiology; American Heart Association Council on Nutrition, Physical Activity, and Metabolism. Resistance exercise in individuals with and without cardiovascular disease: 2007 update: a scientific statement from the American Heart Association Council on Clinical Cardiology and Council on Nutrition, Physical Activity, and Metabolism. Circulation. 2007;116(5):572-84.

50. Yancey AK, Fielding JE, Flores GF, Sallis JF, McCarthy WJ, Breslow L. Creating a robust public health infrastructure for physical activity promotion. Am J Prev Med. 2007;32(1):68-78. 